\title{
Missed Addisonian crisis in surgical wards
}

\author{
M. Small, A.C. MacCuish and J.A. Thomson
}

University Department of Medicine, and Diabetic Unit, Royal Infirmary, 10 Alexandra Parade, Glasgow G31 2ER, $U K$.

\begin{abstract}
Summary: Three women were admitted to the surgical wards with acute gastro-intestinal symptoms and despite good clinical (pigmentation, hypotension) and biochemical (hyponatraemia, acidosis) evidence of Addisonian crisis had unnecessary investigations with delay in the diagnosis and appropriate management of this medical emergency. Clinicians should take careful note of the typical electrolyte upset seen in Addisonian crisis.
\end{abstract}

\section{Introduction}

Although Addison's disease is an uncommon condition with a prevalence in the United Kingdom of 39/ million, ${ }^{1}$ the clinical and biochemical presentation of acute adrenal insufficiency with predominant gastrointestinal symptomatology is well known to undergraduate medical students. We report 3 patients who, over a 3 year period, were admitted to the surgical wards in an Addisonian crisis where a significant delay was noted in making the correct diagnosis.

\section{Case reports}

\section{Case 1}

A 49 year old post-menopausal female was admitted to the general surgical ward in 1985 with a one week history of epigastric pain and vomiting and a six week history of anorexia with weight loss of approximately 8 pounds. In her past medical history she was diagnosed to have mild type 2 (non-insulin dependent) diabetes in 1984 and follow-up at the diabetic clinic had revealed reasonable glycaemic control on dietary measures alone. In 1981 she had presented to the medical wards with haemoptysis, at which time bronchoscopy was negative. At that time she was noted to have facial plethora, central obesity and to be mildly hypertensive, blood pressure (BP) $150 / 100 \mathrm{mmHg}$, but urinary free cortisol levels were normal. At the time of

Correspondence: M. Small, M.D., M.R.C.P., University Department of Medicine, Royal Infirmary, Glasgow G31 2ER, UK.

Accepted: 25 November 1986 her current admission she was obese and unwell with a BP of $70 / 0 \mathrm{mmHg}$, pulse rate $120 / \mathrm{min}$ and epigastric tenderness. Chest X-ray, abdominal X-ray and serum amylase were normal, the plasma glucose was $12 \mathrm{mmol} / \mathrm{l}$ and urea and electrolytes are listed in Table I. Urinalysis showed moderate ketonuria. The patient was thought to have a peptic ulcer and was treated with intravenous cimetidine and fluids. Following $500 \mathrm{ml}$ of $0.9 \%$ saline and $500 \mathrm{ml}$ plasma the BP rose to $100 / 60 \mathrm{mmHg}$ and the patient was given 9 litres of fluid over the subsequent 36 hours. The patient improved following her rehydration, the ketonuria disappeared and gastroscopy, barium enema and ultrasound of the abdomen failed to reveal a cause for her symptoms. Seven days after admission the patient was well and was allowed home. Four days later however she was re-admitted with the same symptoms, haemodynamic and electrolyte upset (Table I). The arterial $\mathrm{pH}$ of 7.30 with a base excess of -14 confirmed metabolic acidosis. The blood glucose was $6.5 \mathrm{mmol} / \mathrm{l}$ and again there was moderate ketonuria. Abdominal X-rays were again negative. The patient was treated with intravenous saline and sodium bicarbonate and 2 days later a medical opinion was sought. The hypotension plus electrolyte disturbance suggested a diagnosis of Addison's disease which was later confirmed.

\section{Case 2}

A 40 year old woman was admitted to the surgical ward with a 6 month history of anorexia, nausea and extreme lethargy and in the 3 months before admission lost over 1 stone in weight. The patient also gave a 10 
month history of oligomenorrhoea. Apart from pigmentation examination was unremarkable. The patient was thought to have a peptic ulcer, and in view of her dehydration and hyponatraemia (Table I) was given 7 litres of $0.9 \%$ saline over the following 48 hours. She improved clinically following re-hydration although the BP had fallen and remained constant at $90 / 50 \mathrm{mmHg}$. Barium meal and gastroscopy were both normal. On the day of her planned discharge, 8 days into her hospital admission, her urea and electrolytes were again found to be abnormal (Table I). The surgical house officer on further enquiry obtained the history that the patient's suntan had not faded following her summer vacation and in fact for cosmetic reasons, she had tried to bleach away the heavy pigmentation in both palmar creases. The house officer suspected Addison's disease which was later confirmed. The patient was transferred to the medical ward, and, following the introduction of corticosteroids and further intravenous fluids made an uneventful recovery.

\section{Case 3}

A 17 year old girl was admitted to the surgical wards with a 2 day history of constant lower abdominal pain, vomiting and sore throat. On examination she was noted to have cervical lymphadenopathy, a pulse rate of $130 / \mathrm{min}$ and BP of $94 / 46 \mathrm{mmHg}$. The abdomen was mildly tender in the right iliac fossa. The urea and electrolytes confirmed dehydration but no comment was made on the other electrolyte disturbance (Table I). The patient was thought to have a viral illness and was treated conservatively with parenteral antiemetics and analgesics and over the following 2 days received 7 litres of intravenous fluids, mainly in the form of $0.9 \%$ saline. She made an uneventful recovery to be discharged 4 days later.

Five months later she was admitted to the medical wards with a similar history of abdominal pain and vomiting and identical haemodynamic upset. She was noted to be pigmented and stated that she had been able to maintain her suntan from 9 months previously and that this was unusual. Her friends had also commented on her pigmentation. The urea and electrolytes were similar to her previous admission (Table 1) and venous gases confirmed a metabolic acidosis with a pH of 7.28 and base excess -8 . The diagnosis of Addison's disease was confirmed and the patient made an uneventful recovery following intravenous saline and corticosteroid administration.

In each of the above 3 cases the diagnosis of Addison's disease was made on undetectable levels of cortisol which failed to increase following short and depot tetracosactrin (Synacthen) test. No patient had evidence of tuberculosis or adrenal calcification on Xray and subsequently adrenal antibodies were detected in all 3 patients. During the period of rehydration and prior to the patients being given corticosteroid therapy, each patient was noted to have mild hypercalcaemia with adjusted calcium values ranging between $2.7-2.9 \mathrm{mmol} / \mathrm{l}$.

\section{Discussion}

These 3 patients were each admitted to the surgicat wards in an Addisonian crisis, because of acute gastrointestinal symptoms, despite the well recognize clinical and biochemical features of Addison's disease being present in each case. Failure to make the correct diagnosis led to unnecessary gastrointestinal investigation and indeed two of the patients were discharged from hospital without the diagnosis of Addison's disease even being contemplated, following clinical recovery after treatment with saline rehydration. Although the first case required re-admission 4 days later, in case 3 it appears likely that a viral illness had precipitated a relative cortisol deficiency and that the patient had sufficient cortisol reserve to remain symptom-free for a further 5 months before being admitted

Table I Urea and electrolyte concentrations (normal values in brackets)

\begin{tabular}{|c|c|c|c|c|c|}
\hline & $\begin{array}{c}N a^{+} \\
(135-145)\end{array}$ & $\begin{array}{c}K^{+} \\
(3.5-5.0)\end{array}$ & $\begin{array}{c}\mathrm{HCO}_{3}^{-} \\
(23-30)\end{array}$ & $\begin{array}{c}\text { Urea } \\
(2.5-8.0)\end{array}$ & $\begin{array}{c}\text { Anion } \\
\text { gap }(<13)\end{array}$ \\
\hline \multicolumn{6}{|l|}{ Case 1} \\
\hline 1st admission & 122 & 4.8 & 14 & 9.7 & 13 \\
\hline 2nd admission & 126 & 5.3 & 13 & 9.9 & 22 \\
\hline \multicolumn{6}{|l|}{ Case 2} \\
\hline On admission & 133 & - & 21 & 11.1 & 13 \\
\hline Day 8 & 132 & 5.1 & 24 & 12.6 & 13 \\
\hline \multicolumn{6}{|l|}{ Case 3} \\
\hline 1st admission & 124 & 5 & 13 & 11.5 & 18 \\
\hline 2nd admission & 116 & 5.9 & 13 & 11.6 & 18 \\
\hline
\end{tabular}

Values are $\mathrm{mmol} / 1$ 
in a similar Addisonian crisis. There is approximately a five-fold excess prevalence of Addison's disease in diabetes compared to the general population. ${ }^{1-3}$ In diabetic patients the development of Addison's disease is usually associated with insulin-dependent diabetes and if such diabetic patients are treated with diet or oral hypoglycaemic agents they often progress to ketosis prone insulin-dependent diabetes, ${ }^{4}$ thus close follow-up of such patients is required.

Our cases also illustrate two other biochemical abnormalities seen in Addisonian crisis, namely metabolic acidosis and hypercalcaemia. The metabolic acidosis is poorly described but it is said that bicarbonate levels of $15-20 \mathrm{mmol} / 1$ are commonly seen in Addisonian crisis. ${ }^{5}$ Our 2 patients who complained of abdominal pain (cases 1 and 3 ) had a more severe acidosis with bicarbonate levels of $13 \mathrm{mmol} / \mathrm{l}$ which occurred despite vomiting with loss of acid from the stomach. The production of the acidosis is related to a renal tubular acidosis with reduced ammonia production due to the hyperkalaemia. ${ }^{6}$ In addition the hypotension and hypovolaemia may have resulted in tissue hypoxia with an increase in unmeasured acids, as suggested by the increased anion gap (see Table I). The first patient presented a more complex metabolic upset - she was an obese, diet-controlled diabetic with anorexia, vomiting, moderate ketonuria, and acidosis despite a relatively normal glucose level. The normoglycaemia and extremely low sodium concentration were out of keeping with the diagnosis of classical diabetic ketoacidosis and should have suggested a further metabolic problem. In diabetic ketoacidosis sodium levels are commonly low ${ }^{1}$ although it would be unusual to find a sodium level of $120 \mathrm{mmol} / \mathrm{l}$. In addition, obese diabetics have elevated insulin levels and are resistant to ketosis and it seems likely that the

\section{References}

1. Stuart Mason, A., Meade, T.W., Lee, J.A.H. \& Morris, J.N. Epidemiological and clinical picture of Addison's disease. Lancet 1968, ii: 744-747.

2. Nerup, J. The clinical and immunological association of diabetes mellitus and Addison's disease. In: Bastenie, P.A., Gepts, W. (eds) Immunity and Autoimmunity in Diabetes Mellitus. Excerpta Medica, Amsterdam 1974, pp. 149-152.

3. Kozak, G.P. Diabetes and other endocrinologic disorders. In: Marble, A., White, P., Bradley, R.F., Krall, L.P. (eds). Joslin's Diabetes Mellitus (11th edition). Philadelphia: Lea and Febiger, 1971, pp.666-694.

4. Irvine, W.J. Immunological aspects of diabetes mellitus: a review (including the salient points of the NDDG report on the classification of diabetes). In: Irvine, W.J. (ed) Immunology of Diabetes. Teviot Scientific Publications, Edinburgh, 1980, pp. 1-53.

5. Bondy, P.K. Disorders of the adrenal cortex. In: Wilson, J.D., Foster, D.W. (eds) Williams Textbook of Endocrinology (7th edition). W.B. Saunders Company, ketonuria in this case was related more to starvation. The improvement, without insulin administration, would support this suggestion. Any diabetic presenting with an acidosis and relatively normal glucose levels should however receive intravenous insulin and hypertonic glucose to correct the acidosis in addition to any other appropriate intravenous fluid therapy.

Transient hypercalcaemia is a well recognized, although uncommon, feature of acute adrenal insufficiency ${ }^{8,9}$ which is due to the effect of glucocorticoid deficiency leading to decreased calcium excretion and probably increased bone resorption. ${ }^{10}$ The findings of hypercalcaemia in our cases suggest that it is more common than the $6 \%$ of cases noted in a previous study. ${ }^{8}$

One further point which requires emphasis is that the degree of fluid replacement required in our patients appeared to be out of keeping with the elevation in the baseline urea levels. In Addison's disease volume depletion seldom exceeds $10 \%$ of the total body fluid. ${ }^{5}$ The large replacement volumes needed to correct the postural hypotension and hyponatraemia therefore suggest a more severe metabolic decompensation.

In $1885^{11}$ Addison described an 'irritability of the stomach and a peculiar change of colour of the skin'. In patients who present in medical as well as surgical wards with these clinical phenomena, and exhibit the characteristic biochemical abnormalities of acute adrenal insufficiency, there should be no undue delay in the diagnosis of this medical emergency.

\section{Acknowledgement}

We wish to thank Mrs M. Tucker for typing the manuscript.

Philadelphia, 1985, pp.816-890.

6. Sebastian, A., Schambelan, M., Lindenfeld, S. \& Curtis Morris, R: Amelioration of metabolic acidosis with fludrocortisone therapy in hyporeninemic hypoaldosteronism. N Engl J Med 1977, 297: 576-583.

7. Johnston, D.G. \& Alberti, K.G.M.M. Diabetic emergencies; practical aspects of the management of diabetic ketoacidosis and diabetes during surgery. Clin Endocrinol Metab 1980, 9: 437-460.

8. Nerup, J. Addison's disease - clinical studies. A report of 108 cases. Acta Endocrinol 1974, 76: 127-141.

9. Downie, W.W., Gunn, A., Paterson, C.R. \& Howie, G.F.A. Hypercalcaemic crisis as presentation of Addison's disease. Br Med J 1977, 1: 145-146.

10. Muls, E., Bouillon, R., Boelaert, J., Lamberigts, G., Van Imschoot, S., Daneels, R. \& De Moore, P. Etiology of hypercalcaemia in a patient with Addison's disease. Calcif Tissue Int 1982, 34: 523-526.

11. Addison, T. On the constitutional and local effects of disease of the suprarenal capsules. Higley, London, 1855. 